\title{
Osteochondroma of the Sella Turcica Presenting With Intratumoral Hemorrhage
}

\author{
-Case Report-
}

\author{
Tomoo InOUE, Noboru TAKAHASHI, Kensuke MURAKAMI, \\ Shinjitsu NishIMURA, Mitsuomi KAIMORI*, and Michiharu NiSHIJIMA
}

Departments of Neurosurgery and *Pathology, Aomori Prefectural Central Hospital, Aomori

\begin{abstract}
A 29-year-old man presented with a primary sellar turcica osteochondroma manifesting as intratumoral hemorrhage mimicking pituitary apoplexy. The patient suffered sudden onset of headache concomitant with vision loss in the left eye. Radiography and computed tomography detected destruction and calcification of the sellar turcica. Magnetic resonance imaging revealed a heterogeneously enhanced suprasellar mass that had elevated and compressed the optic chiasm. The preoperative diagnosis was hemorrhagic pituitary adenoma, craniopharyngioma, meningioma, or chordoma based on the signal heterogeneity of the lesion. To relieve the symptoms and make a definitive diagnosis, surgical removal via a basal interhemispheric approach was carried out. The tumor was not totally removed because of tight adhesion to the pituitary stalk, but postoperative ophthalmological examination revealed improvement of the visual disturbance. The histological diagnosis was osteochondroma based on the presence of mature chondrocytes and osteomatous tissue. Osteochondroma should be included in the differential diagnosis of tumors with acute hemorrhage in the sella turcica.
\end{abstract}

Key words: osteochondroma, intratumoral hemorrhage, sellar turcica, pituitary apoplexy, magnetic resonance imaging

\section{Introduction}

Osteochondroma is the most common type of benign skeletal neoplasm which arises in any part of the body and consists of two main elements: cartilaginous cap and underlying osseous component such as mature trabecular bone. ${ }^{2-4,6-26,28-31,33)}$ Osteochondroma can occur as a solitary lesion, or as part of Ollier disease (multiple polysystemic enchondromatosis) or Maffuci's syndrome (multiple enchondromatosis associated with soft tissue angiomas). ${ }^{4,22)}$ Intracranial osteochondroma is a benign tumor considered to originate from the residual primordial cartilaginous cranium that replaces the spheno-petrosal, spheno-occipital, or petro-occipital synchondrosis during development, ${ }^{2-4,14,15,20,22,26,28,30}$ and occurs as a cartilage-capped bony protrusion on the external surface bones.7,11,16,19) Radiography shows intracranial osteochondroma as a well- demarcated, lobulated, dense mass that continues to the underlying bone. ${ }^{1-4,6-26,28-31,33)}$ Intracranial osteochondromas are rare, accounting for less than $1 \%$ of all intracranial space-occupying lesions, ${ }^{4,12)}$ and can arise from the skull base, convexity, and other intracranial regions. ${ }^{2-4,6,12-15,19-22,25,26,28-31)}$ The vast majority of intracranial osteochondromas occur at the base of the skull and can be categorized into three groups: sellar turcica osteochondroma, parasellar osteochondroma, and clival osteochondroma. ${ }^{2-4,14,15,20,22,26,28,30)}$

Here we describe an unusual case of sellar turcica osteochondroma mimicking hemorrhagic pituitary adenoma.

\section{Case Report}

A 29-year-old man complained to a local ophthalmologist of a gradual decline in the bilateral

Received February 13, 2008; Accepted August 5, 2008

Author's present address: T. Inoue, M.D., Department of Neurosurgery, Tohoku University Graduate School of Medicine, Sendai, Miyagi, Japan. 


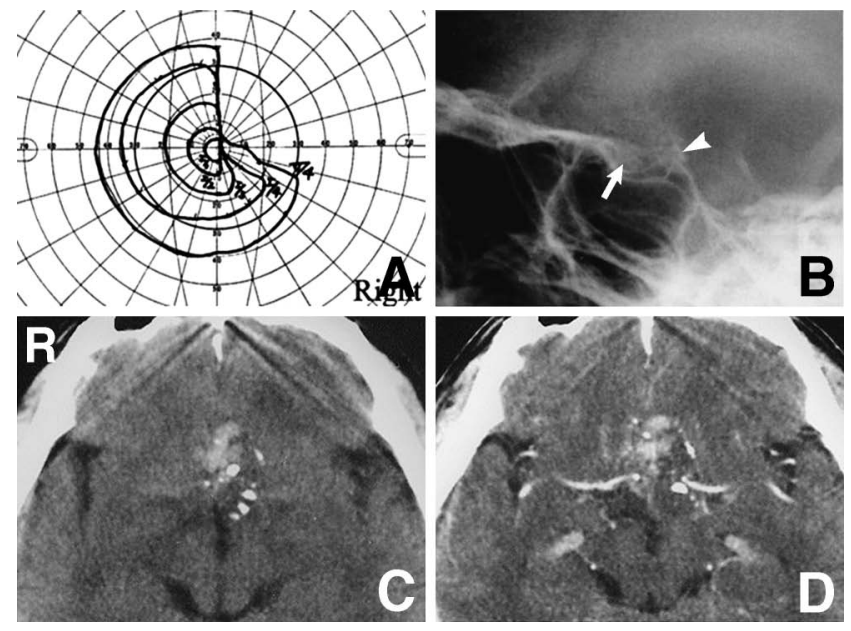

Fig. 1 A: Ophthalmological examination revealing temporal superior quadrantanopsia of the right eye. B: Skull radiograph demonstrating suprasellar destruction (arrow) and calcification (arrowhead). C, D: Computed tomography scans showing a hemorrhagic suprasellar lesion with slight calcification (C), and enhancement with contrast medium (D).

visual fields. The patient received conservative treatment without intracranial examination for 3 years. $\mathrm{He}$ then suffered acute onset of thunderclap headache and progressive loss of vision in his left eye, resulting in a visit to our hospital.

Ophthalmological examination disclosed total blindness of the left eye and temporal superior quadrantanopsia of the right eye (Fig. 1A). No other neurological deficits including the other cranial nerves were identified. Endocrine examinations revealed only decreased levels of adrenocorticotropic hormone. Skull radiography showed suprasellar destruction and calcification (Fig. 1B). Computed tomography revealed a hemorrhagic suprasellar lesion with slight calcification, and slight enhancement with contrast medium (Fig. 1C, D).

Sagittal $\mathrm{T}_{1}$-weighted magnetic resonance (MR) imaging demonstrated a mass in the enlarged sellar turcica appearing hyperintense in the anterior-superior aspect and hypointense in the posterior-inferior aspect, with slight enhancement by gadoliniumdiethylenetriaminepenta-acetic acid (Gd-DTPA) (Fig. 2A, B). $\mathrm{T}_{2}$-weighted $\mathrm{MR}$ imaging revealed a hypointense area consistent with the hyperintense region on $\mathrm{T}_{1}$-weighted $\mathrm{MR}$ imaging, indicating the presence of intratumoral hemorrhage, and a hyperintense area consistent with the hypointense region on $\mathrm{T}_{1}$-weighted imaging, suggesting the presence of a cartilaginous lesion (Fig. 2A, C). Axial
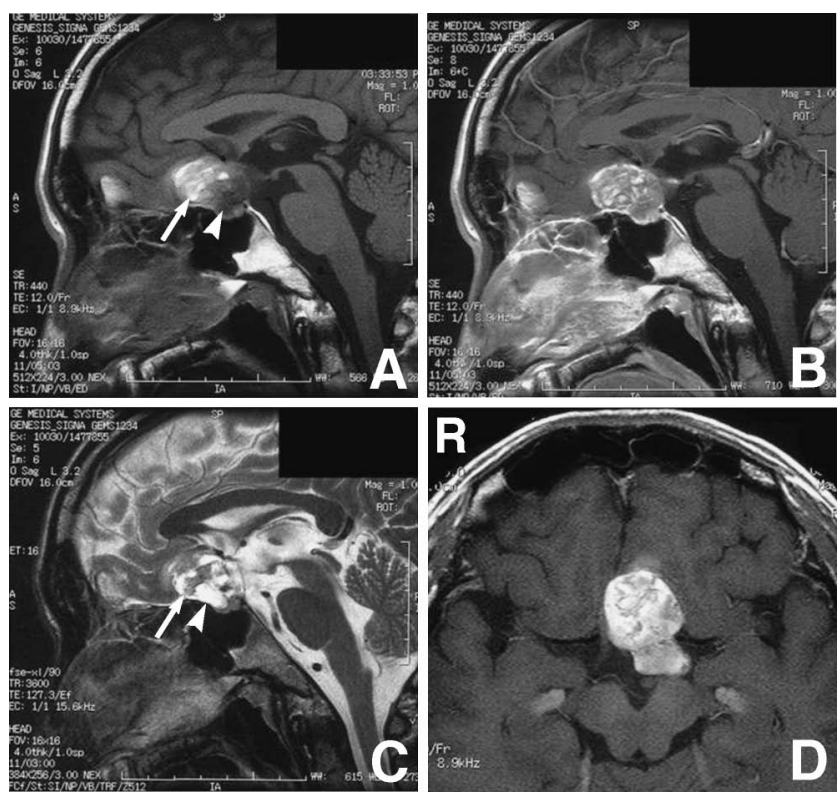

Fig. 2 A-C: Sagittal $T_{1^{-}}(A)$ and $T_{2}$-weighted (C) magnetic resonance (MR) images revealing a lesion as heterogeneous intensity in the sellar turcica, with slight enhancement by gadolinium-diethylenetriaminepenta-acetic acid (Gd-DTPA) (B). $\mathrm{T}_{2}$-weighted MR image revealing a hypointense area consistent with the hyperintense region (A, C: arrow) on $T_{1}$-weighted MR images, indicating the presence of an intratumoral hemorrhage, and a hyperintense area consistent with the hypointense region (A, C: arrowhead) on $\mathrm{T}_{1^{-}}$ weighted images, suggesting the presence of a cartilaginous lesion. D: Axial $\mathrm{T}_{1}$-weighted MR image with Gd-DTPA revealing the tumor extending to the left cerebral peduncle.

$\mathrm{T}_{1}$-weighted $\mathrm{MR}$ imaging with Gd-DTPA revealed that the heterogeneous intensity mass extended to the left cerebral peduncle (Fig. 2D). The preoperative diagnosis was hemorrhagic pituitary adenoma, craniopharyngioma, meningioma, or chordoma.

A bifrontal basal osteoplastic craniotomy was performed. The white capsule of the tumor was incised to remove the reddish and partially calcified lesion piecemeal, leading to adequate internal decompression. The tumor was friable but easily aspirated. The left subfrontal approach revealed the tumor elevating the optic chiasm. Disengagement of the optic nerve was achieved, but the lesion adhered tightly to the pituitary stalk and could not be totally removed. Histological examination showed that the tumor consisted of well-differentiated osteomatous, chondromatous tissues and intratumoral hemorrhage (Fig. 3A). Photomicrographs of the tumor showed 


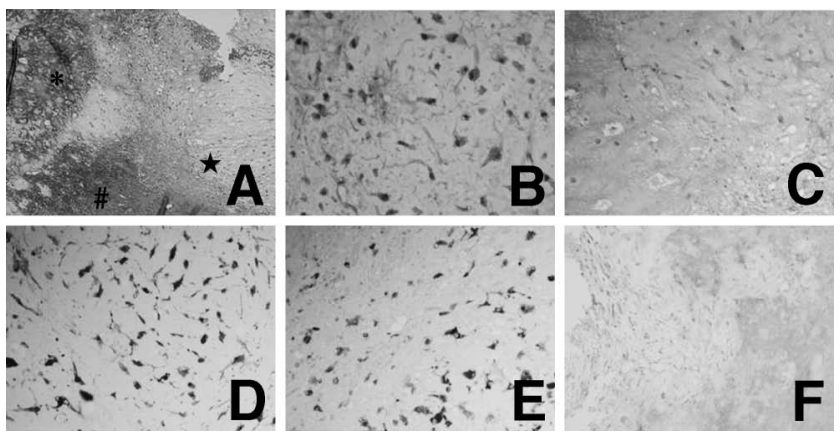

Fig. 3 A, B: Photomicrographs demonstrating a well-differentiated osteomatous (A, asterisk) and chondromatous (A, star) lesion including hyaline cartilage and chondrocytes with homogeneous small nuclei (B). Intratumoral hemorrhage was observed (A, hash mark). Hematoxylin and eosin stain, original magnification A: $\times 100$, B: $\times 400$. C-E: Immunohistochemistry was positive for Alcian blue (C), S-100 protein (D), and neuronspecific enolase (E). $\times 400$. F: Ki-67 labeling index was $1 \%$. $\times 100$.

hyaline cartilage and chondrocytes with homogeneous small nuclei (Fig. 3B). The myxoid material was positive for Alcian blue (Fig. 3C). Immunohistochemistry was positive for S-100 protein and neuron-specific enolase (Fig. 3D, E). Ki-67 labeling index was $1 \%$ (Fig. 3F). The histological diagnosis was osteochondroma.

The decompression of the optic nerves and chiasm resulted in the improvement of visual acuity. The patient was doing well at 5 years after surgery, with no neurological deterioration or recurrence on MR imaging.

\section{Discussion}

Skull base osteochondromas show the same benign histological features as other solitary osteochondromas. Osteochondroma tumor masses grow more slowly than other suprasellar tumors such as chondrosarcoma, metastatic tumors, meningioma, craniopharyngioma, or chordoma ${ }^{21,33)}$ and usually do not show clinical symptoms until they become large enough to induce mass effects. ${ }^{2-4,6-26,28-31,33)}$ Osteochondromas can cause symptomatic complications via mechanical irritation of the cranial nerves, soft tissue compression, vascular injury, and fracture. ${ }^{17)}$ The specific symptomatology depends on tumor localization, and the range of symptoms is wide. Sellar turcica osteochondroma is related to optic chiasmal syndrome, which is characterized by irregular bitemporal hemianopsia, inferior quadran- tanopsia, and decreased visual acuity. ${ }^{28)}$ Parasellar and clival osteochondromas are associated with pareses of the third, fourth, fifth, and sixth cranial nerves, and increased tumor volumes can possibly lead to lower cranial nerve pareses, cerebellar ataxia, or pyramidal tract signs.9,15) Pain or discomfort can occur due to disturbance of the surrounding sensory nerves and connective tissue. ${ }^{26)}$

The symptoms of osteochondroma generally show gradual onset, but our patient suffered sudden onset of severe headache and loss of vision that might have been due to intratumoral hemorrhage. Osteochondroma with intracranial hemorrhage is rare ${ }^{9,33)}$ and the present case of sellar turcica osteochondroma with acute intratumoral hemorrhage mimicking pituitary apoplexy is unique. Symptomatic pituitary hemorrhage is usually associated with large adenomas and seldom with other sellar turcica tumors. ${ }^{32)}$ Hemorrhage in pituitary adenoma may be caused by vascular insufficiency as a result of rapid tumor growth, as tumor progression surpasses the available blood supply and compresses the stalk and portal vessels, which could possibly lead to hemorrhagic infarction and necrosis. ${ }^{32)}$ The cause of intratumoral hemorrhage in osteochondroma has not been established, but we speculate that a similar mechanism to that occurring in adenoma may have been involved in our case. The tumor might have eroded the vasculature with resultant hemorrhage, and growth may have outstripped the vascular supply, causing ischemic necrosis. This degeneration may have caused fulminant tumor expansion, leading to the acute onset of severe headache and visual disturbance that resembled pituitary apoplexy.

Apoplectic sellar turcica tumors with hemorrhagic infarction such as pituitary adenomas, craniopharyngiomas, and Rathke cleft cysts show variable MR imaging intensity, ${ }^{5,27,32)}$ but characteristic MR imaging findings for sellar turcica osteochondroma with hemorrhage have not been previously reported. Few reports of MR imaging of non-hemorrhagic osteochondroma are available, ${ }^{10,13,19,23,24,30)}$ and observations include high intensity on $\mathrm{T}_{1}$-weighted $\mathrm{MR}$ imaging due to extension of fatty marrow into the tumor, ${ }^{10)}$ mixed laminated high and low intensity of the mass on both $\mathrm{T}_{1}$ - and $\mathrm{T}_{2}$-weighted images, ${ }^{19)}$ central high intensity on $\mathrm{T}_{1^{-}}$and $\mathrm{T}_{2}$-weighted images surrounded by a ring of low intensity, ${ }^{23)}$ and an irregular, well-demarcated mass appearing as high intensity on $\mathrm{T}_{1}$-weighted images and reticular mixed intensity on $\mathrm{T}_{2}$-weighted images. ${ }^{30}$ Osteochondroma has a cartilaginous cap that appears as intermediate to low signal intensity on $\mathrm{T}_{1}$-weighted images as a result of higher water content, as well as high signal 
intensity on $\mathrm{T}_{2}$-weighted images ${ }^{24)}$ (Fig. 2A, C). In our case, the major portion of the tumor was visualized as a heterogeneously intense area on $\mathrm{T}_{1^{-}}$and $\mathrm{T}_{2^{-}}$ weighted images, which may reflect intratumoral bleeding, abundant fat tissue, and bony trabeculae.

Total surgical removal is considered to be the only effective treatment for osteochondroma, ${ }^{3,12-15,19,21,26)}$ but the present tumor adhered tightly to the pituitary stalk, making total removal impossible. We found that partial removal relieved the compression of the optic chiasm and nerve. The histological specimens showed no malignancy and the latest MR imaging revealed no recurrence. However, annual follow ups should continue to detect malignant transformation. ${ }^{1,31)}$

The present case suggests that osteochondroma should be considered in the differential diagnosis of tumors with acute intratumoral hemorrhage in the sellar region.

\section{References}

1) Altay M, Bayrakci K, Yildiz Y, Erekul S, Saglik Y: Secondary chondrosarcoma in cartilage bone tumors: report of 32 patients. J Orthop Sci 12: 415-423, 2007

2) Bakdash H, Alksne JF, Rand RW: Osteochondroma of the base of the skull causing an isolated oculomotor nerve paralysis. Case report emphasizing microsurgical techniques. J Neurosurg 31: 230-233, 1969

3) Becelli R, Saltarel A, Santamaria S, Mastellone P, Gwanmesia I, Cianfrone F, Frati R: A case report of osteochondroma of the frontotemporosphenoidal suture. J Exp Clin Cancer Res 23: 147-151, 2004

4) Berkmen YM, Blatt ES: Cranial and intracranial cartilaginous tumours. Clin Radiol 19: 327-333, 1968

5) Binning MJ, Liu JK, Gannon J, Osborn AG, Couldwell WT: Hemorrhagic and nonhemorrhagic Rathke cleft cysts mimicking pituitary apoplexy. J Neurosurg 108: 3-8, 2008

6) Castillo M, Hudgins PA, Hoffman JC Jr: Lockjaw secondary to skull base osteochondroma: CT findings. $J$ Comput Assist Tomogr 13: 338-339, 1989

7) Cobby M, Watt L: Tumours and tumour-like conditions of bone, in Sutton D (ed): Textbook of Radiology and Imaging. London, Churchill Livingstone, 2003, pp 1276-1278

8) Cohen EK, Kressel HY, Frank TS, Fallon M, Burk DL Jr, Dalinka MK, Schiebler ML: Hyaline cartilage-origin bone and soft-tissue neoplasms: MR appearance and histologic correlation. Radiology 167: 477-481, 1988

9) Crawford SC, Cornell SH, Franken EA Jr: General case of the day. Intracranial osteochondroma. Radiographics 7: 1178-1180, 1987

10) Giudici MA, Moser RP Jr, Kransdorf MJ: Cartilaginous bone tumors. Radiol Clin North Am 31:
237-259, 1993

11) Greenfield GB: The solitary lesion, in Greenield GB (ed): Radiology of Bone Diseases. Philadelphia, JB Lippincott, 1988, pp 629-632

12) Haddad GF, Haddad FS, Zaatari G: Dural osteochondroma: case report, review of the literature and proposal of a new classification. Br J Neurosurg 12: 380-384, 1998

13) Hatayama T, Sekiya T, Suzuki S, Iwabuchi T: [A case of intracranial osteochondroma: its MR images]. No Shinkei Geka 17: 1063-1066, 1989 (Jpn, with Eng abstract)

14) Himuro H, Suzuki H, Takeyama E, Jinbo $M$, Kitamura K: [A case of intracranial osteochondroma (author's transl)]. No Shinkei Geka 5: 1079-1083, 1977 (Jpn, with Eng abstract)

15) Ikeda $Y$, Shimura $T$, Higuchi $H$, Nakazawa $S$, Sugisaki Y: [Intracranial osteochondroma-case report (author's transl)]. No Shinkei Geka 8: 263-269, 1980 (Jpn, with Eng abstract)

16) Jayakumar PN, Devi BI, Shenoy SN, Santosh V, Shankar SK: Thoracic spinal osteochondroma causing cord compression: A report of five cases. Indian Journal of Radiology and Imaging 2: 117-120, 1998

17) Karasick D, Schweitzer ME, Eschelman DJ: Symptomatic osteochondromas: imaging features. AJR Am J Roentgenol 168: 1507-1512, 1997

18) Lee JK, Yao L, Wirth CR: MR imaging of solitary osteochondromas: report of eight cases. AJR Am J Roentgenol 149: 557-560, 1987

19) Lin WC, Lirng JF, Ho DM, Chang FC, Shing-Su C, Luo CB, Teng MM, Chang CY: A rare giant intracranial osteochondroma. Zhonghua Yi Xue Za Zhi (Taipei) 65: 235-238, 2002

20) List CF: Osteochondromas arising from base of skull. Surg Gynecol Obstet 76: 480-492, 1943

21) Mashiyama S, Sakurai Y, Kayama T, Nishino A, Jokura H: [A case of intracranial osteochondroma originating with psychomotor epilepsy]. No Shinkei Geka 22: 165-168, 1994 (Jpn, with Eng abstract)

22) Matz S, Israeli Y, Shalit MN, Cohen ML: Computed tomography in intracranial supratentorial osteochondroma. J Comput Assist Tomogr 5: 109-115, 1981

23) Moriwaka F, Hozen H, Nakane K, Sasaki H, Tashiro K, Abe H: Myelopathy due to osteochondroma: MR and CT studies. J Comput Assist Tomogr 14: 128-130, 1990

24) Murphey MD, Choi JJ, Kransdorf MJ, Flemming DJ, Gannon FH: Imaging of osteochondroma: variants and complications with radiologic-pathologic correlation. Radiographics 20: 1407-1434, 2000

25) Nagai S, Yamamoto N, Wakabayashi K, Emura I, Takeuchi F, Umemori T, Sato S, Endo S: Osteochondroma arising from the convexity dura mater. Case illustration. J Neurosurg 88: 610, 1998

26) Padhya TA, Athavale SM, Kathju S, Sarkar S, Mehta AR: Osteochondroma of the skull base. Otolaryngol Head Neck Surg 137: 166-168, 2007

27) Piotin M, Tampieri D, R fenacht DA, Mohr G, Gar- 
ant M, Del Carpio R, Robert F, Delavelle J, Melanson D: The various MRI patterns of pituitary apoplexy. Eur Radiol 9: 918-923, 1999

28) Richards WW, Thompson MC: Suprasellar osteochondroma with chiasmal syndrome. Arch Ophthalmol 65: 437-441, 1961

29) Saito T, Utsunomiya T, Furutani $M$, Yamamoto $H$ : Osteochondroma of the mandibular condyle: a case report and review of the literature. J Oral Sci 43: 293-297, 2001

30) Sato K, Kodera T, Kitai R, Kubota T: Osteochondroma of the skull base: MRI and histological correlation. Neuroradiology 38: 41-43, 1996

31) Vezeau PJ, Fridrich KL, Vincent SD: Osteochondroma of the mandibular condyle: literature review and report of two atypical cases. J Oral Maxillofac Surg
53: 954-963, 1995

32) White W, Liu SS: Pituitary apoplexy, in Carter LP, Spetzler RF (eds): Neurovascular Surgery. New York, McGraw-Hill, 1994, pp 497-519

33) Yamaguchi T, Wada S, Matsukado Y: [Intracranial giant osteochondroma with unusual clinical features]. No Shinkei Geka 11: 181-184, 1983 (Jpn, with Eng abstract)

Address reprint requests to: Tomoo Inoue, M.D., Department of Neurosurgery, Tohoku University Graduate School of Medicine, 1-1 Seiryo-machi, Aoba-ku, Sendai 980-8574, Japan. e-mail: tomoo49@gmail.com 